\title{
A systematic review of common genetic variation and biological pathways in autism spectrum disorder
}

\author{
Diego Alejandro Rodriguez-Gomez', Danna Paola Garcia-Guaqueta', Jesús David Charry-Sánchez', \\ Elias Sarquis-Buitrago ${ }^{1}$, Mariana Blanco ${ }^{1}$, Alberto Velez-van-Meerbeke ${ }^{1,2}$ and Claudia Talero-Gutiérrez ${ }^{1,2^{*}}$ (D)
}

\begin{abstract}
Background: Autism spectrum disorder (ASD) is a complex neurodevelopmental condition characterized by persistent deficits in social communication and interaction. Common genetic variation appears to play a key role in the development of this condition. In this systematic review, we describe the relationship between genetic variations and autism. We created a gene dataset of the genes involved in the pathogenesis of autism and performed an overrepresentation analysis to evaluate the biological functions and molecular pathways that may explain the associations between these variants and the development of ASD.

Results: 177 studies and a gene set composed of 139 were included in this qualitative systematic review. Enriched pathways in the over-representation analysis using the KEGG pathway database were mostly associated with neurotransmitter receptors and their subunits. Major over-represented biological processes were social behavior, vocalization behavior, learning and memory. The enriched cellular component of the proteins encoded by the genes identified in this systematic review were the postsynaptic membrane and the cell junction.
\end{abstract}

Conclusions: Among the biological processes that were examined, genes involved in synaptic integrity, neurotransmitter metabolism, and cell adhesion molecules were significantly involved in the development of autism.

Keywords: Autism Spectrum Disorder, Pathophysiology, Polymorphisms, Genetics, Synapsis

\section{Background}

Autism spectrum disorder (ASD) is a neurodevelopmental condition characterized by persistent deficits in social communication and interaction, in addition to various restrictive and repetitive behaviors [1-3]. Several twin and family-based studies have shown that ASD is highly heritable. However, the specific genetic mechanisms that underlie this heritability are not yet fully understood [26]. Increasing evidence suggests that the bulk of genetic

\footnotetext{
*Correspondence: claudia.talero@urosario.edu.co

${ }^{1}$ Neuroscience Research Group (NeURos), NeuroVitae Center for Neuroscience, School of Medicine and Health Sciences, Universidad del Rosario, Carrera 24 No. 63C-69, 111221 Bogotá D.C., Colombia Full list of author information is available at the end of the article
}

risk associated with ASD may be due to single nucleotide polymorphisms (SNPs) and copy number variants (CNVs), rather than specific single-gene mutations or syndromic conditions, which constitute only approximately $5-15 \%$ of ASD cases [5].

The identification of common genetic variants associated with the etiology of ASD has increasingly been used as a strategy to understand the mechanisms underlying this condition. Multiple family-based case-series and case-control studies around the world have identified common genetic variants that account for a portion of our understanding of ASD. However, these studies are typically directed towards the identification of common genetic variants in one or a few specific genes associated 
with ASD. The larger picture of the pathophysiology of ASD requires this information to be integrated into one or multiple genetic and molecular pathways that can provide further insights into the mechanisms that drive ASD.

The proper functioning of the brain and central nervous system requires appropriate synaptic morphology and function $[7,8]$. Common genetic variations in candidate genes and their interactions within multiple biochemical and cellular pathways have revealed that synaptic and neurotransmitter dysfunction are essential components in the development of ASD [7-9]. Indeed, various neurologic and psychiatric diseases, including schizophrenia, Alzheimer's disease, and ASD, have been associated with synaptic and neurotransmitter dysfunction [8].

Several studies have addressed the role played by synaptic alterations in the etiology of ASD [8-11]. A significant proportion of the genetic variation that has been described in ASD patients has been associated with genes that are either directly or indirectly involved in synaptic structure and function $[9,10]$. This review aims to provide an overview of the known genetic variations and their contributions to biological pathways involved in ASD such as synaptic and neurotransmitter dysfunction.

\section{Methods}

\section{Study design}

This study was performed as a systematic review of the literature. The protocol registration can be found under the PROSPERO ID CRD42020206689.

\section{Search strategy}

To identify relevant articles for inclusion in this systematic review, a search was performed in PubMed using the following MeSH terms: ("Autism Spectrum Disorder," OR "Autistic disorder," OR "Rett Syndrome") AND "Polymorphisms (Genetics)." Additionally, the search results were filtered using three criteria: (1) studies published during the last 20 years (2000-2020), (2) studies performed only in humans, and (3) studies written in English. Additionally, the references for each included paper were reviewed to identify relevant citations that were retrieved manually using Google Scholar and PubMed.

\section{Study selection}

Articles were included in our systematic review if they fulfilled the following study criteria: (1) Patients with an ASD diagnosis, according to the Diagnostic and Statistical Manual of Mental Disorders criteria (DSM-IV or DSM-5), the International Classification of Diseases (ICD) criteria, Childhood Autism Rating Scale (CARS), Autism Diagnostic Interview-Revised (ADI-R), or other scales specifically designed to assess ASD. (2) Genetic testing strategies to identify SNPs, CNVs, or other genetic variants in either one or multiple ASD candidate genes. (3) Case-control studies, family-based case series, or case reports performed using human subjects. Patients with tuberous sclerosis or fragile $\mathrm{X}$ syndrome were excluded since these conditions are associated with specific mechanisms and genetic variants.

During the study selection process, articles were filtered first by title and then by reading the abstracts. This process was performed by the leading author, and the results were discussed with all the members of the team during weekly meetings. Disagreements were resolved by discussion or independent review by a second author.

\section{Quality assessment}

Quality assessment was performed using the Joanna Briggs Institute clinical appraisal tools. Studies were divided among all the team members, and the results of the quality assessment were discussed during weekly meetings. The reasons for article exclusion based on quality were always explicitly considered. In case of doubt, the article was independently reviewed by a second author. Any additional disagreement was resolved by discussion among the members of the team.

\section{Data extraction}

Data were extracted from the included articles to obtain the following information: study design, characteristics of the studied population, study objective, genetic tests performed, genes studied, and variations identified. A data set of genes associated with ASD and common genetic variations was generated for the over-representation analysis. Genes and genetic variants were included in the data set when a significant positive association was identified between the studied SNP or CNV and the presence of ASD.

\section{Over-representation analysis}

The biological interpretation of identified genes was performed using the Functional Annotation Tool from the Database for Annotation, Visualization, and Integrated Discovery (DAVID) [12, 13]. Within DAVID, the Kyoto Encyclopedia of Genes and Genomes (KEGG), Gene Ontology (GO) Biological Process (BP), and GO Cellular Component $(\mathrm{CC})$ databases were chosen for the overrepresentation analysis. The data set of genes obtained was analyzed against the human genome background to identify whether the proportion of genes within the data set was higher than the one expected by chance in each of the biological pathways of the selected databases. For this analysis, the EASE score was set to be lower than 0.05 in order to define statistically significant enrichment. This value was calculated as a conservative modified Fisher's 
exact $\mathrm{p}$-value that removes one gene within each given category and then calculates the exact Fisher probability for that category. As a result, the EASE score penalizes the significance of categories with few genes, which favors more robust categories in the over-representation analysis [14]. Bonferroni correction using the Bonferroni Šidák p-value provided by DAVID was also included. An additional over-representation analysis of biological pathways was conducted using the Reactome database, [15] and Fisher's exact p-values were calculated to complement the results obtained in DAVID.

\section{Results}

\section{Search results and study characteristics}

A total of 941 articles were identified using the initial search criteria, including those manually retrieved. After removing duplicated papers and articles written in other languages, 862 articles remained. These records were screened by title and abstract, and 227 articles were selected for full-text assessment. From these articles, 30 were excluded due to negative results, and 20 were excluded due to the inclusion of syndromic or irrelevant cases. Finally, 177 studies were included in this qualitative systematic review (Fig. 1). During data extraction, a gene set composed of 139 genes was generated, each associated with several SNPs. Other genetic variants identified within the selected studies included CNVs and microdeletions. Further information regarding each study and the genes identified for inclusion in the gene set can be found in the Additional file 1 for this paper.

Almost all of the included studies were either casecontrol studies or family-based case series. These studies were conducted among different populations; the Chinese Han ethnicity was the most commonly studied population, appearing in 35 (19.77\%) articles. Other populations that were frequently studied included the Autism Genetic Resource Exchange from the United States (30 articles; 16.94\%), the Iranian population (10

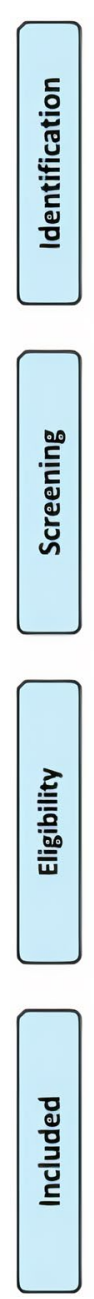

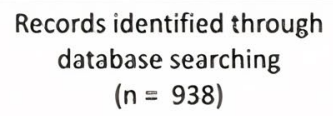

Additional records identified through other sources $(n \leq 3)$

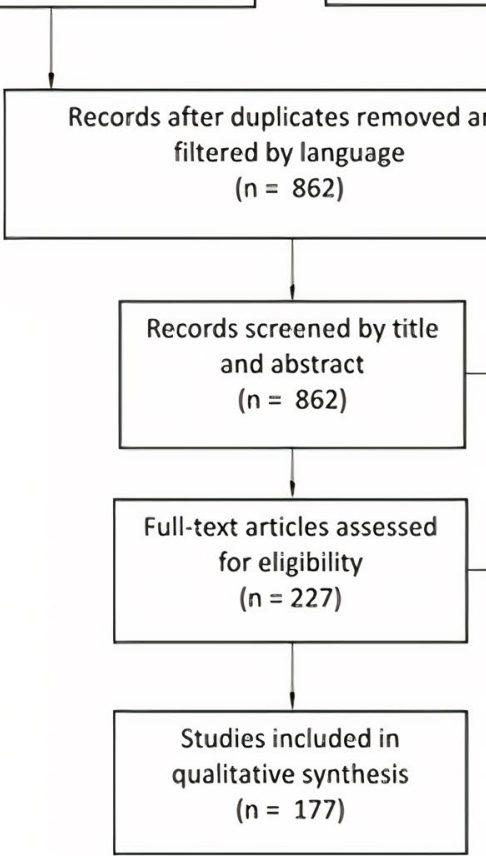

Full-text articles excluded, with reasons

Negative results $(n=30)$ Not relevant or syndromic cases $(n=20)$

Fig. 1 PRISMA flow diagram for the studies included in the systematic review 
articles; 5.64\%) and the Korean population (9 articles; 5.08\%). The studies also examined cohorts from Egypt, Iran, Saudi Arabia, and several European countries. In most cases, the diagnosis of ASD was based on the DSMIV or DSM-5 criteria; however, several other tools, such as the ADI-R and CARS, were also used.

\section{Results of the over-representation analysis}

An over-representation analysis was performed using DAVID and the gene set that was generated from the data extraction process. The most significant terms that were enriched in our gene set using the KEGG pathway database are shown in Table 1. Most of the enriched pathways were associated with either a type of chemical synapse or a process associated with synaptic function. Some of the genes associated with these pathways included genes that encode neurotransmitter receptors and their subunits, such as serotonin receptors (HTR2A and HTR3A), $\gamma$-aminobutyric acid (GABA)-A receptors (GABRA4, GABRA5, GABRB1, GABRB3, GABRG2, and GABRG3), glutamate receptors (GRIN2A, GRIN2B, GRIK2, GRIK5 and GRM7), dopamine receptors (DRD1, DRD2 and $D R D 3)$, and oxytocin receptors (OXTR). Neurotransmitter metabolism genes were also identified, including dihydroxyphenylalanine (DOPA) decarboxylase (DDC) and monoamine oxidase genes (MAOA and $M A O B)$.

When the analysis was performed using the GO Biological Process (GOBP) database, several terms associated with ASD were over-represented, including social behavior, vocalization behavior, learning, and memory. Some of the genes associated with these terms encode neurexins (NRXN1 and NRXN2), neuroligins (NLGN4X and NLGN4Y), cell adhesion molecules (NRCAM), and molecular scaffolding proteins that are involved in the postsynaptic density of neurotransmitter receptors (SHANK2 and SHANK3. The most significant terms enriched using the GOBP database are summarized in Table 2.

The cellular localization of the genes identified in this systematic review was assessed using the GO Cellular Component (GOCC) database. The over-enrichment analysis showed that the two most enriched terms were "postsynaptic membrane" $\left(\mathrm{p}=1.1 \times 10^{-15}\right)$ and "cell junction" $\left(\mathrm{p}=1.8 \times 10^{-11}\right)$. Other significantly enriched terms included "plasma membrane" $\left(\mathrm{p}=2.6 \times 10^{-10}\right)$, "neuron projection" $\left(\mathrm{p}=2 \times 10^{-8}\right)$, and "postsynaptic density" $\left(\mathrm{p}=1.1 \times 10^{-7}\right)$.

An additional over-representation analysis was performed using the Reactome database. From the 118 initially extracted genes, 90 were found in the database, and 483 pathways were hit by at least one gene. A probability score was calculated and corrected using the Benjamini-Hochberg method for false discovery rates (FDRs) to obtain the most enriched pathways for the gene set. The ten most significant pathways, sorted by p-value, are shown in Table 3. The results obtained in this analysis were consistent with those obtained using DAVID. The enriched pathways were primarily associated with synaptic structure and function, and neurexins, neuroligins, neurotransmitter receptors, and synaptic interactions were all enriched in our gene set. Additionally, various pathways associated with transcription and synaptic regulation that are mediated by $M E C P 2$ were also significantly enriched in this analysis.

Table 1 Results of the over-representation analysis using the KEGG Pathway database

\begin{tabular}{|c|c|c|c|c|}
\hline Term & $\#$ & Genes & p-value & Bonferroni \\
\hline Serotonergic synapse & 13 & $\begin{array}{l}\text { HTR2A, HTR3A, CACNA1C, DDC, GABRB1, GABRB3, MAOA, MAOB, PLA2G4C, PTGS2, } \\
\text { PRKCB, SLC6A4, TPH2 }\end{array}$ & $3.4 \times 10^{-8}$ & $3.2 \times 10^{-6}$ \\
\hline Neuroactive ligand-receptor interaction & 19 & $\begin{array}{l}\text { HTR2A, ADRB2, AVPR1A, DRD1, DRD2, DRD3, GABRA4, GABRA5, GABRB1, GABRB3, } \\
\text { GABRG2, GABRG3, GRIN2A, GRIN2B, GRIK2, GRIK5, GRM7, OXTR, VIPR2 }\end{array}$ & $3.6 \times 10^{-8}$ & $3.2 \times 10^{-6}$ \\
\hline Calcium signaling pathway & 14 & $\begin{array}{l}\text { HTR2A, ATP2B2, ADRB2, AVPR1A, CACNA1C, CACNA1G, CHRNA7, DRD1, GRIN2A, } \\
\text { NOS2, OXTR, PRKCB, SLC25A6 }\end{array}$ & $9.9 \times 10^{-7}$ & $3.0 \times 10^{-5}$ \\
\hline Dopaminergic synapse & 12 & $\begin{array}{l}\text { CACNA1C, DDC, DRD1, DRD2, DRD3, GRIN2A, GRIN2B, MAOA, MAOB, PRKCB, } \\
\text { PPP2R5D, SLC18A1 }\end{array}$ & $1.4 \times 10^{-6}$ & $3.5 \times 10^{-5}$ \\
\hline GABAergic synapse & 9 & ABAT, CACNA1C, GABRA4, GABRA5, GABRB1, GABRB3, GABRG2, GABRG3, PRKCB & $2.1 \times 10^{-5}$ & $4.8 \times 10^{-4}$ \\
\hline Glutamatergic synapse & 10 & $\begin{array}{l}\text { SHANK2, SHANK3, CACNA1C, GRIN2A, GRIN2B, GRIK5, GRM7, HOMER1, PLA2G4C, } \\
\text { PRKCB }\end{array}$ & $2.7 \times 10^{-5}$ & $5.3 \times 10^{-4}$ \\
\hline Retrograde endocannabinoid signaling & 9 & CACNA1C, GABRA4, GABRA5, GABRB1, GABRB3, GABRG2, GABRG3, PTGS2, PRKCB & $7.5 \times 10^{-5}$ & $1.3 \times 10^{-3}$ \\
\hline Tryptophan metabolism & 7 & ASMT, AADAT, DDC, MAOA, MAOB, TDO2 & $2.1 \times 10^{-4}$ & $3.5 \times 10^{-3}$ \\
\hline
\end{tabular}

Significant terms using Bonferroni correction are included. Other disease processes are not presented in this table

KEGG Kyoto encyclopedia of genes and genomes, GABA $\gamma$-aminobutyric acid 
Table 2 Results of the over-representation analysis using the GO Biological Process (BP) database

\begin{tabular}{|c|c|c|c|c|}
\hline Term & $\#$ & Genes & p-value & Bonferroni \\
\hline Social behavior & 13 & $\begin{array}{l}\text { SHANK2, SHANK3, AVPR1A, CNTNAP2, DRD3, MECP2, NRXN1, NRXN2, NLGN4X, } \\
\text { NLGN4Y, OXTR, PTCHD1, SLCGA4 }\end{array}$ & $1.5 \times 10^{-15}$ & $2 \times 10^{-12}$ \\
\hline Vocalization behavior & 7 & SHANK2, SHANK3, CNTNAP2, DLG4, NRXN1, NRXN2, NLGN4X, NLGN4Y & $5.5 \times 10^{-10}$ & $7.5 \times 10^{-7}$ \\
\hline Adult behavior & 8 & SHANK2, SHANK3, CNTNAP2, GABRG2, GRM7, NRXN1, NRXN2, NLGN4X & $8.2 \times 10^{-10}$ & $1.1 \times 10^{-6}$ \\
\hline Synapse assembly & 10 & SHANK2, SHANK3, BDNF, DRD1, DRD2 MECP2, NRXN1, NRXN2, NLGN4Y, NRCAM & $9.3 \times 10^{-10}$ & $1.3 \times 10^{-6}$ \\
\hline Memory & 10 & HTR2A, CX3CR1, SHANK2, SHANK3, CHRNA7, DRD1, GRIN2A, OXTR, PTGS2, SLC6A4 & $1.2 \times 10^{-8}$ & $1.7 \times 10^{-5}$ \\
\hline $\begin{array}{l}\text { Positive regulation of synaptic } \\
\text { transmission, glutamatergic }\end{array}$ & 7 & SHANK2, SHANK3, DRD1, NRXN1, OXTR, PTGS2, RELN & $4.8 \times 10^{-9}$ & $6.6 \times 10^{-6}$ \\
\hline Learning & 9 & SHANK2, SHANK3, CNTNAP2, DRD1, DRD3, NRXN1, NLGN4X, NLGN4Y, PTGS2 & $1.2 \times 10^{-8}$ & $1.7 \times 10^{-5}$ \\
\hline Vocal learning & 5 & SHANK3, CNTNAP2, FOXP2, NRXN1, NRXN2 & $1.2 \times 10^{-7}$ & $1.6 \times 10^{-4}$ \\
\hline Long-term synaptic potentiation & 7 & SHANK2, SHANK3, DRD1, GRIN2A, MECP2, RELN, SNAP25 & $4.3 \times 10^{-7}$ & $5.9 \times 10^{-4}$ \\
\hline Chemical synaptic transmission & 12 & $\begin{array}{l}\text { HTR2A, CACNA1G, GABRA5, GRIN2A, GRIN2B, GRIK2, GRM7, HOMER1, NRXN1, } \\
\text { NRXN2, SLC6A4, SNAP25 }\end{array}$ & $2.6 \times 10^{-6}$ & $3.6 \times 10^{-3}$ \\
\hline
\end{tabular}

The ten most significant terms using Bonferroni correction are included

GO gene ontology

Table 3 Results of the over-representation analysis using the Reactome database

\begin{tabular}{|c|c|c|c|}
\hline Term & $\#$ & Genes & p-value \\
\hline Neuronal system & 28 & $\begin{array}{l}\text { ABAT, ACE, CDH8, EGF, GABRA4, GABRA5, GABRB1, GABRB3, GABRG2, GABRG3, GRIK2, } \\
\text { GRIN2A, GRIN2B, HOMER1, HTR3A, KCNJ10, MAOA, NLGN4X, NLGN4Y, NRXN1, NRXN2, } \\
\text { PRKCB1, DLG4, SHANK2, SHANK3, SLC6A4, SNAP25, STX1A }\end{array}$ & $1.11 \times 10^{-16}$ \\
\hline Neurexins and neuroligins & 11 & $\begin{array}{l}\text { GRIN2A, GRIN2B, HOMER1, NLGN4X, NLGN4Y, NRXN1, NRXN2, DLG4, SHANK2, } \\
\text { SHANK3, STX1A }\end{array}$ & $6.25 \times 10^{-14}$ \\
\hline Transmission across Chemical Synapses & 20 & $\begin{array}{l}\text { ABAT, ACE, EGF, GABRA4, GABRA5, GABRB1, GABRB3, GABRG2, GABRG3, GRIK2, } \\
\text { GRIN2A, GRIN2B, HTR3A, KCNJ10, MAOA, PRKCB1, DLG4, SLC6A4, SNAP25, STX1A }\end{array}$ & $7.85 \times 10^{-12}$ \\
\hline Protein-protein interaction at synapses & 11 & $\begin{array}{l}\text { GRIN2A, GRIN2B HOMER1, NLGN4X, NLGN4Y, NRXN1, NRXN2, DLG4, SHANK2, } \\
\text { SHANK3, STX1A }\end{array}$ & $1.41 \times 10^{-11}$ \\
\hline Transcriptional Regulation by MECP2 & 5 & BDNF, GRIN2A, GRIN2B, MECP2, MET & $4.91 \times 10^{-10}$ \\
\hline MECP2 regulates neuronal receptors and channels & 4 & GRIN2A, GRIN2B, MECP2, MET & $1.56 \times 10^{-9}$ \\
\hline $\begin{array}{l}\text { Neurotransmitter receptors and postsynaptic } \\
\text { signal transmission }\end{array}$ & 14 & $\begin{array}{l}\text { EGF, GABRA4, GABRA5, GABRB1, GABRB3, GABRG2, GABRG3, GRIK2, GRIN2A, GRIN2B, } \\
\text { HTR3A, KCNJ10, PRKCB1, DLG4 }\end{array}$ & $1.72 \times 10^{-9}$ \\
\hline GABA receptor activation & 8 & EGF, GABRA4, GABRA5, GABRB1, GABRB3, GABRG2, GABRG3, KCNJ10 & $2.99 \times 10^{-8}$ \\
\hline
\end{tabular}

The most significant pathways, according to $p$-value, are included

\section{Discussion}

Multiple common genetic variants have been described among various ASD patient cohorts. Most previous studies have explored the effects of mutations in specific genes or protein alterations that may enhance our understanding of ASD. Previous studies have categorized the disorder as a synaptopathy and have attempted to describe how aberrant synapse function can contribute to neurodevelopmental disorders. [7] In this systematic review, we created a data set containing genes that have been associated with ASD in several studies worldwide. By performing an over-representation analysis of these genes, we found that genetic variants related with synaptic function, among others, may be implicated in the pathophysiology of ASD.
Genes that encode neurotransmitter receptors comprise a significant portion of our data set. In particular, several genes involved in the synthesis of GABA-A receptors were found to be altered in ASD. Associations between polymorphisms in GABRA4, $G A B R B 1$, and GABRA2, which are all located in the $4 p 12$ region, were reported in Argentinian, [16] Caucasian American, [17] and African American populations. [18] Haplotype formation and interactions with other genes, such as GABRB2 in chromosome 5, were also identified [16, 18]. Moreover, SNPs and mutations in GABRB3, GABRA5, and GABRG3, which are located in the 15q11-q13 region, were found to be associated with ASD in Korean and American populations [19-22]. Although many of these polymorphisms are intronic 
and their biological significance is not yet completely understood [16], the disruption of transmembrane chloride transport may significantly impact neuronal excitability and neurodevelopment [23]. Some previously described SNPs and mutations associated with the identified genes and chromosomal regions have also been associated with other neurological conditions, including epilepsy, Angelman syndrome (AS), and fragile-X syndrome [23].

The transmission disequilibrium test (TDT) revealed significant preferential transmission for SNPs in the GRIK2 gene in European (rs2518261) and Korean (rs3213607) populations [24, 25]. This gene encodes a subunit of glutamate kainate receptors and has been associated with synaptic plasticity, memory, and learning $[24,25]$. The disruption of glutamatergic receptors was also demonstrated in studies of GRIN2A and GRIN2B. A study examining 19 polymorphisms in GRIN2B reported the significant transmission and linkage disequilibrium (LD) of various SNPs and one haplotype among the Chinese Han population [26]. Moreover, an intronic polymorphism in GRIN2A was also preferentially transmitted during the TDT test in a European sample [27]. These genes encode subunits of N-methyl-D-aspartate (NMDA) receptors, which are responsible for sodium transport across the postsynaptic plasma membrane and have been associated with intellectual disability and epilepsy [28]. Additionally, a common genetic variation in the GRM7 gene (rs779867), which encodes a metabotropic glutamatergic receptor, was also preferentially transmitted among Irani patients with ASD [29].

The term "serotonergic synapse" was also significantly enriched in our over-representation analysis using the KEGG pathway database. SNPs in HTR2A (rs6311 and rs6313) were significantly associated with ASD in Korean and Croatian populations, and an SNP in HTR3A (rs1150220) was identified in an American population [30-32]. The polymorphisms rs6311 and rs6313 have been extensively studied in association with several neuropsychiatric conditions, including schizophrenia and Alzheimer's disease [33,34]. Although their influence on ASD development remains unclear, previous studies have suggested a possible role because the 5HT-2A receptor is the primary excitatory serotonin receptor subtype, suggesting that these SNPs may also be associated with cognitive processes, such as attention, learning, and memory [35].

The identification of hyperserotonemia in patients with ASD has also led to the investigation of the long and short variants in the 5-HTT-linked polymorphic region (5HTTLPR) of the SLC6A4 gene. This gene encodes the sodium-dependent serotonin transporter (SERT), which is a presynaptic protein that allows for the reuptake of serotonin that is released into the synaptic cleft [31, 36-39]. These studies found the increased transmission of either the short $(S)$ or the long ( $\mathrm{L}$ ) variant, depending on the population being studied. In Korean and Israeli children, the preferential transmission of the $\mathrm{L}$ allele was identified, with significant $\mathrm{LD}$, and the $\mathrm{L} / \mathrm{L}$ genotype was associated with ASD [31, 39]. In contrast, among South African, Indian, Irish, and American children, the increased transmission of the $\mathrm{S} / \mathrm{S}$ genotype and the $\mathrm{S}$ allele were observed [36, 38, 40,41]. Several other genetic variants in the SLC6A4 gene that might confer an increased risk for ASD have been reported. The rs6355 variant (Gly56Ala) was identified in American subjects [42], SNPs in the 3' untranslated region (UTR) were found in an Indian population $[41,43]$, and a variable number tandem repeat (VNTR) in intron 2 was reported in Irish patients [40].

The dopaminergic synapse was one of the terms enriched in the over-representation analysis that was performed using the KEGG pathways database. Several ASD-related genes were associated with this type of synapse, including $D R D 1$ and $D R D 3$, which encode the D1 and D3 dopamine receptors, respectively $[44,45]$. In a North American population, the rs265981-C, rs4532$\mathrm{A}$, and rs686-T alleles, as well the C-A-T haplotype, for the DRD1 gene, were over-transmitted from mothers to affected sons in the TDT analysis and were associated with social interaction and nonverbal communication difficulties [45]. Similarly, in a European population examining Dutch and British subjects, a significant association was identified between the rs167771 SNP in the DRD3 gene and the presence of ASD [44]. Common genetic variations in genes encoding voltage-dependent calcium channels, such as CACNA1C and CACNA1G, were also found in a Chinese Han and an American population, respectively $[46,47]$.

An increased risk of ASD has also been associated with polymorphisms in the OXTR gene, which encodes the oxytocin receptor. Multiple SNPs and haplotypes on OXTR have been described in American [48], Chinese Han [49], Israeli [50], and Japanese [51] samples. Interestingly, Hernandez et al. identified reduced functional connectivity between the nucleus accumbens and other areas of the reward circuit as a function of increased OXTR risk-allele dosage in patients with ASD [48]. Additionally, Lerer et al. reported a significant association between various OXTR SNPs and haplotypes and ASD, IQ, and the Vineland Adaptive Behavior Scales, which suggested that genetic variations in the OXTR gene may play roles in several cognitive processes required for daily living skills [50]. These results are consistent with the enrichment of the OXTR in the terms "social behavior" and 
"memory" in our over-representation analysis using the GOBP database.

Several genes involved in neurotransmitter metabolism were identified in the over-representation analysis using both the KEGG pathway and Reactome databases. The $D D C$ gene encodes the aromatic L-amino acid decarboxylase $(A A D C)$ or DOPA decarboxylase, which is important for decarboxylation reactions that occur during the formation of dopamine, histamine, and serotonin. A recent study performed in a northern Spanish sample found a significant association between ASD and both the rs6592961 SNP and a four-marker haplotype in this gene [52]. Genetic variations in the monoamine oxidase genes $M A O A$ and $M A O B$ have also been reported [53, 54]. In particular, a haplotype composed of three SNPs in the MAOA gene was significantly associated with ASD in a Korean sample [54], whereas the rs2283727 and rs2283728 SNPs in the $M A O B$ gene were identified in Indian ASD patients [53]. The $M A O B$ SNPs were also associated with increased platelet 5-HT levels and CARS scores for specific behavioral symptoms [53]. The significance of these genetic variants have yet to be fully elucidated. However, these genes have also been implicated in several other neuropsychiatric conditions, and these associations provide further insight into the roles played by metabolic pathways in the pathophysiology of ASD [55-57].

A candidate-gene screening study performed in a European sample revealed two SNPs in the $A B A T$ gene, which encodes the GABA-catabolizing enzyme 4-aminobutyrate aminotransferase, that were significantly associated with ASD in both simplex and multiplex families [27]. In addition, the C677T and A1298C variants in the MTHFR gene were significantly associated with ASD in three different populations of Indian, Chinese, and Canadian American descent $[51,58,59]$. The MTHFR gene encodes methylenetetrahydrofolate reductase, an enzyme that is involved in the metabolism of folate and the conversion of homocysteine into methionine [60]. These variants have been widely studied in association with mild hyperhomocysteinemia and increased cardiovascular risk [60-62], but they also appear to be involved in the maintenance of brain structure and function and may also be associated with ASD [63]. A graphic representation of the ASD-related genes associated with neurotransmitter receptors, metabolism, and other synaptic functions is illustrated in Fig. 2.

Tryptophan metabolism was one of the most significantly enriched terms in the over-representation analysis performed in this study. The rs375910 SNP in the

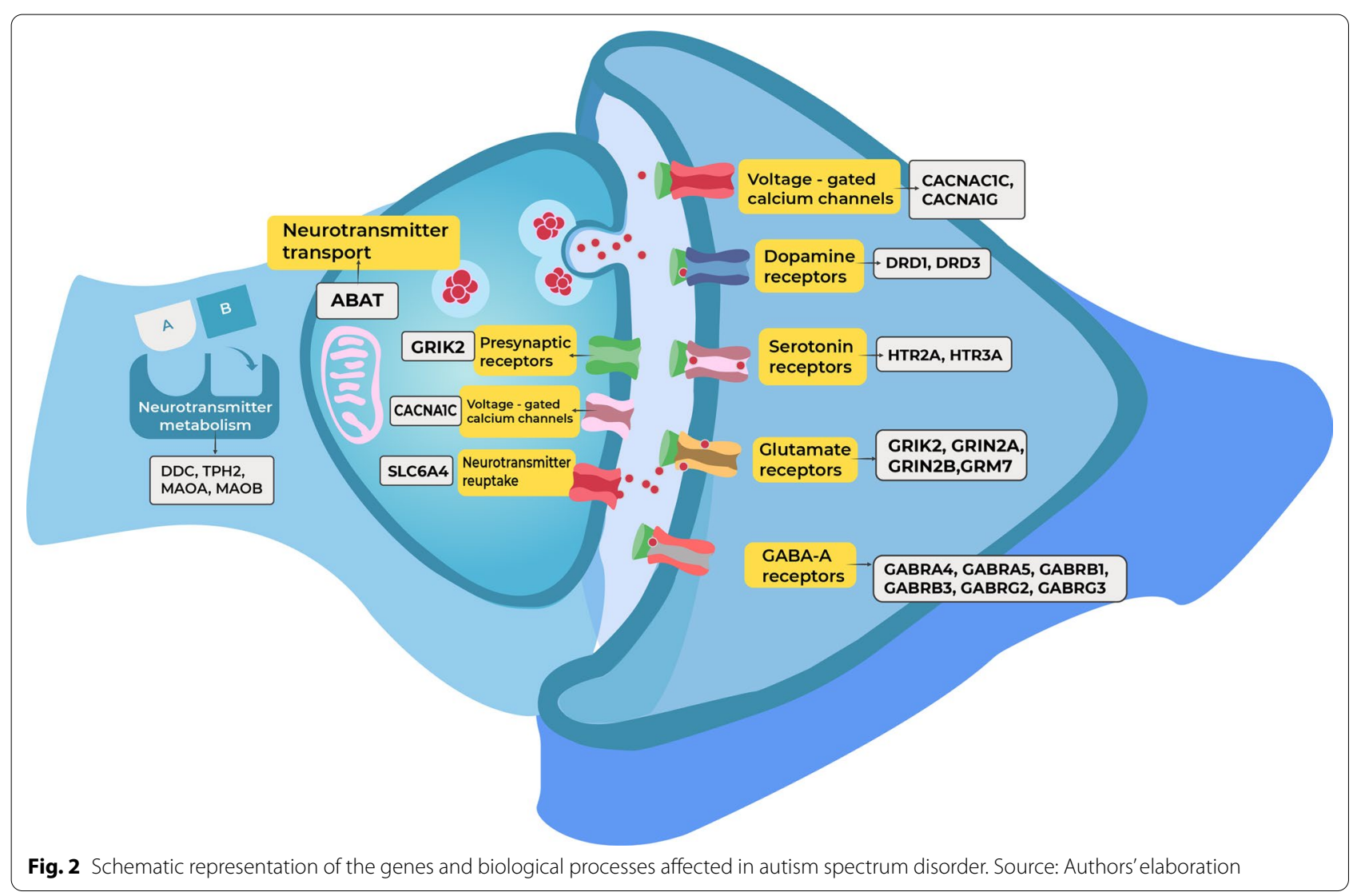


tryptophan 2,3-dioxygenase gene (TDO2) was overtransmitted in patients with ASD from an American sample [64]. Similarly, two intronic SNPs (rs4341581 and rs11179000) in the tryptophan hydroxylase-2 gene (TPH2) were significantly associated with ASD in a casecontrol study performed among American individuals of European descent [65]. The rs5989681 and rs4446909 SNPs and several haplotypes in the ASMT gene were associated with ASD and autistic-like traits in two European samples [66, 67]. The ASMT gene encodes for the final enzyme required for melatonin biosynthesis, which suggests that these findings may partially explain the association between ASD and sleep disorders [66, 67]. Altogether, these results indicate the existence of various defects in tryptophan metabolism and may help explain the altered serotonin levels in patients with ASD, since tryptophan is a serotonin precursor. However, further investigations regarding these polymorphisms remain necessary as some of these associations have failed to be replicated in larger samples, such as those reported for the TPH2 gene [68].

Another significant proportion of our gene set is represented by synaptic cell-adhesion molecules, including neurexins (NRXNs) and neuroligins (NLGNs). These molecules mediate signaling between pre- and postsynaptic specializations and, thus, play a significant role in information processing. Alterations in these genes have been associated with ASD and other cognitive diseases [69]. CNTNAP2 encodes a member of the NRXN family, and its association with ASD has been widely studied, especially rs7794745, which was found to be associated with ASD in Iranian and Brazilian patients [70, 71]. This SNP was also identified as a component of haplotype T-A (rs7794745-rs10500171) and haplotype A-T-A (rs10244837-rs7794745-rs10500171), which were both associated with ASD in a Chinese Han sample [72]. In our over-expression analysis, the CNTNAP2 gene was found in the terms "social behavior," "learning," "vocalization behavior," and "vocal learning," which are all consistent with some of the most important features of ASD.

Contactin-associated-proteins, such as that encoded by CNTNAP2, play major roles in extrasynaptic neuronglia interactions, and NRXNs and NLGNs form a transsynaptic complex that is essential for the appropriate formation and development of synapses. Interactions between presynaptic NRXNs and postsynaptic NLGNs mediate trans-synaptic cell adhesion and shape synaptic efficacy and plasticity [69]. Common genetic variations in NRXN1, NRXN2, and NRXN3 were evaluated in two cohorts of Chinese Han patients, which revealed significant associations between ASD and the rs2303298 T allele in NRXN1 and rs12273892 AT genotype in NRXN2 $[73,74]$. The study by Wang et al. also found that the rs12879016 polymorphism in the NRXN3 gene might play a significant protective role in ASD [74]. In contrast, in a European population, a haplotype formed by six polymorphisms on the $N L G N 4 X$ gene was significantly associated with ASD (Odds Ratio=3.58) [75]. Various point mutations that affect the NRXN and NLGN genes were also reported in European and Chinese patients with ASD, suggesting that the genetic influences of these cellular adhesion molecules in ASD may be derived from both less disruptive polymorphisms and more disruptive missense mutations that affect protein structure and function [75-77].

Scaffolding proteins encoded by the SHANK gene family play a significant role in postsynaptic organization through the formation of complexes containing postsynaptic receptors, ion channels, NRXNs, and NLGNs [78, 79]. SHANK2 and SHANK3 have been proposed as candidate genes in ASD, and SHANK3 mutations have been described at a frequency of $1 \%$ in ASD cases [80]. These genes are present in most of the enriched terms in our biological processes over-expression analysis (Table 2). High genetic variations in SHANK3 were identified in the Autism Genetic Resource Exchange sample, together with HOMER1 variants. These molecules interact and regulate metabotropic, NMDA, and AMPA glutamate receptors, mediating synaptic plasticity [81]. In addition, CNVs in region 22q13.3 involving SHANK3 dosage were found in three Taiwanese patients: a de novo terminal deletion of approximately $106 \mathrm{~kb}$ at $22 q 13.33$, a de novo interstitial duplication of approximately $1.8 \mathrm{Mb}$ at 22q13.32-q13.33, and a microdeletion of approximately $147 \mathrm{~kb}$ at $22 q 13.33$ [82]. Another study involving Italian and US ASD patients found five potentially pathogenic alterations, resulting in a mutation rate of $2.3 \%$, which was twice the previously reported frequency of deleterious SHANK3 mutations [83]. Fewer studies were identified examining SHANK2; however, the SNP rs7671730 in this gene has been reported to be associated with ASD in a Chinese sample, and multiple haplotypes containing more than 5 SNPs have also been significantly associated with ASD risk [84].

Signaling molecules have also been studied as candidate genes for ASD, such as RELN, which encodes reelin, a glycoprotein related to neuronal migration that is found in the developing brain [85]. Various SNPs have been described in this gene, with variations among populations due to ethnic differences [86]. However, common variations include rs736707, which was associated with ASD risk in a Caucasian cohort [87] and among South African ASD patients [88]. Moreover, in a Chinese Han sample, the CC haplotype, composed of rs736707-rs2229864, was significantly associated with ASD [89]. Persico et al. found that longer triplet repeats 
in the 5'UTR conferred an increased vulnerability to ASD in Italian and US patients [90], and similar results were later described by Skaar et al. [91].

The mechanisms and molecular interactions underlying the pathophysiology of ASD remain incompletely understood. However, by analyzing the genes and biological pathways identified in this systematic review it is possible to provide insight into some of the functions and cellular mechanisms involved. Polymorphisms in genes encoding glutamatergic receptors and calcium-regulated ion channels may be associated with increased excitotoxicity in patients with ASD. This mechanism has previously been proposed as a major contributor to synaptic dysfunction through mitochondria-mediated cell damage in ASD [92]. Impaired GABAergic signaling resulting from genetic variation in GABA receptors may contribute to synaptic dysfunction through excitation-inhibition imbalance. Moreover, excitatory GABAergic signaling during the embryonic and early postnatal stages regulates neuronal migration and synapsis development, which appear to be impaired in patients with ASD [93].

Early brain overgrowth and defects in the formation of neural circuits have been observed in ASD. This association may be explained by genetic variation in genes associated with synaptic structure and development such as scaffolding molecules and cell adhesion molecules [93]. Neurexin-neuroligin interactions have been shown to promote neurotransmitter clustering and cytoskeletal polymerization that promotes adequate synaptic structures in the developing brain [94]. Evidence from animal models has shown that $\operatorname{Nrxn} 1 \alpha$, Shank3, and Nrxn $2 \alpha$ knockout mice display autismrelated behaviors, which may be explained by modifications that favor synaptic dysfunction $[95,96]$.

Glial cells also appear to play an important role in the pathophysiology of ASD. Evidence of increased microglial density in the cerebral cortex and increased levels of proinflammatory molecules in subjects with ASD support the association between microglial activation and neuronal dysfunction [97]. Although proinflammatory pathways were not significantly enriched in the over-representation analysis, several genes that are preferentially expressed in glial cells were identified. This includes genes involved with neurotransmitter metabolism such as $A B A T, M A O A$, and MAOB, as well as genes that encode for scaffolding proteins and transcriptional regulators. Furthermore, the enrichment of calcium signaling pathways and the identification of genes that encode for NMDA and metabotropic glutamate receptors suggests that disruption of synaptic modulation and plasticity via gliotransmitters may also be impaired in ASD [98].

\section{Conclusions}

The pathophysiology of ASD involves multiple genetic, environmental, and developmental influences. Although the specific mechanisms that drive ASD remain unclear, the current understanding of the genetic variants involved in this condition point towards synaptic dysfunction as one of those mechanisms. [3, 93] In this systematic review, we used an over-representation analysis to identify and describe some of the biological processes and molecular pathways involved in the pathophysiology of ASD. Many of the genetic variants described in our review can be found in one of three groups of genes that may be involved in the pathophysiology of ASD: (1) neurotransmitter receptors, (2) genes involved in neurotransmitter metabolism, and (3) cell adhesion molecules and scaffolding proteins.

We described SNPs associated with all major synapse types, including serotonergic, dopaminergic, GABAergic, and glutamatergic synapses. Moreover, we discussed genetic variants in the gene encoding the oxytocin receptor, which appears to play a significant role in ASD [49, $50,99]$. Genes involved in the metabolism of neurotransmitters, especially tryptophan metabolism, which results in serotonin synthesis, also appear to play key roles in the development of ASD. Altered genes in the metabolic pathways of neurotransmitters may explain various findings in ASD, including hyperserotonemia [31, 36-39] and sleep disorders, due to the altered production of melatonin $[66,67]$. These hypotheses have encouraged research projects with potential therapeutic alternatives, such as the use of melatonin, although no significant benefit of this intervention has been identified $[66,67]$. Recently, genes that encode cell adhesion molecules and scaffolding proteins have been among the most studied. Knowledge of the function and biological significance of these molecules continues to evolve, and their importance in the adequate formation and development of synapses is increasingly recognized [69].

Among the limitations of this systematic review, some of the populations examined were studied in several articles; as a result, overlapping in the subjects of two or more studies may have occurred. Due to the heterogeneity and complexity of genetic data, further statistical analysis was not performed. Our search was directed towards case-series and population-based studies aiming to identify genetic variation in different populations and use primary data from clinical studies. The scope of this review was to describe and explore some of the pathways involved in autism that may be associated with common genetic variation. Therefore, the findings described in this review suggest that encouraging further investigation into synaptic dysfunction may be critical for achieving a better understanding of ASD. 


\section{Supplementary Information}

The online version contains supplementary material available at https://doi. org/10.1186/s12868-021-00662-z.

Additional file 1. Database of genes associated with ASD in this systematic review.

\section{Acknowledgements}

We thank Lisa Giles, PhD, from Edanz Group (https://en-author-services.edanz. $\mathrm{com} / \mathrm{ac}$ ) for editing a draft of this manuscript. We thank Universidad del Rosario for sponsoring the English edition of this manuscript.

\section{Authors' contributions}

All the authors (DARG, DPG, JDC, ESB, MB, AVVM, CTG) conceived and designed the systematic review. DAR and DG performed the search and filtered the articles by title and abstract. All the authors (DARG, DPG, JDC, $\mathrm{ESB}, \mathrm{MB}, \mathrm{AVVM}, \mathrm{CTG}$ ) participated in the critical appraisal and full-text filter of the selected articles. All the authors (DARG, DPG, JDC, ESB, MB, AVVM, CTG) participated in weekly meetings for discussion of the results obtained and were a major contributor in writing the manuscript, and read and approved the final manuscript.

\section{Funding}

The authors did not receive support from any organization for the submitted work.

\section{Availability of data and materials}

The datasets generated and analyzed in this study can be found in the supplemental data to enable others to perform similar studies and replicate our findings. Further information is available from the corresponding author under reasonable request.

\section{Declarations}

Ethics approval and consent to participate

Not applicable.

\section{Consent for publication}

Not applicable.

\section{Competing interests}

The authors declare that they have no competing interests.

\section{Author details}

${ }^{1}$ Neuroscience Research Group (NeURos), NeuroVitae Center for Neuroscience, School of Medicine and Health Sciences, Universidad del Rosario, Carrera 24 No. 63C-69, 111221 Bogotá D.C., Colombia. ${ }^{2}$ NeuroVitae Center for Neuroscience, School of Medicine and Health Sciences, Universidad del Rosario, Carrera 24 No. 63C-69, 111221 Bogotá D.C., Colombia.

Received: 30 June 2021 Accepted: 16 September 2021

Published online: 09 October 2021

\section{References}

1. American Psychiatric Association. Diagnostic and statistical manual of mental disorders. Fifth Edition. American Psychiatric Association; 2013 [cited 2020 Nov 25]. https://psychiatryonline.org/doi/book/https://doi. org/10.1176/appi.books.9780890425596

2. Gaugler T, Klei L, Sanders SJ, Bodea CA, Goldberg AP, Lee AB, et al. Most genetic risk for autism resides with common variation. Nat Genet. 2014:46(8):881-5

3. Lord C, Brugha TS, Charman T, Cusack J, Dumas G, Frazier T, et al. Autism spectrum disorder. Nat Rev Dis Primer. 2020;6(1):5.

4. Betancur $\mathrm{C}$. Etiological heterogeneity in autism spectrum disorders: more than 100 genetic and genomic disorders and still counting. Brain Res. 2011:1380:42-77.
5. Pinto D, Pagnamenta AT, Klei L, Anney R, Merico D, Regan R, et al. Functional impact of global rare copy number variation in autism spectrum disorders. Nature. 2010;466(7304):368-72.

6. The DDD Study, Homozygosity Mapping Collaborative for Autism, UK10K Consortium, The Autism Sequencing Consortium, De Rubeis S, He X et al. Synaptic, transcriptional and chromatin genes disrupted in autism. Nature. 2014:515(7526):209-15.

7. Lepeta K, Lourenco MV, Schweitzer BC, Martino Adami PV, Banerjee P, Catuara-Solarz S, et al. Synaptopathies: synaptic dysfunction in neurological disorders-a review from students to students. J Neurochem. 2016;138(6):785-805

8. Verpelli C, Montani C, Vicidomini C, Heise C, Sala C. Mutations of the synapse genes and intellectual disability syndromes. Eur J Pharmacol. 2013:719(1-3):112-6.

9. Yoo H. Genetics of autism spectrum disorder: current status and possible clinical applications. Exp Neurobiol. 2015;24(4):257-72.

10. GiovedÃ S, Corradi A, Fassio A, Benfenati F. Involvement of synaptic genes in the pathogenesis of autism spectrum disorders: the case of synapsins. Front Pediatr. 2014. https://doi.org/10.3389/fped.2014.00094/abstract.

11. Zoghbi HY. Postnatal neurodevelopmental disorders: meeting at the synapse? Science. 2003;302(5646):826-30.

12. Huang DW, Sherman BT, Lempicki RA. Systematic and integrative analysis of large gene lists using DAVID bioinformatics resources. Nat Protoc. 2009;4(1):44-57.

13. Huang DW, Sherman BT, Lempicki RA. Bioinformatics enrichment tools: paths toward the comprehensive functional analysis of large gene lists. Nucleic Acids Res. 2009;37(1):1-13.

14. Hosack DA, Dennis G, Sherman BT, Lane HC, Lempicki RA. Identifying biological themes within lists of genes with EASE. Genome Biol. 2003;4(10):R70

15. Jassal B, Matthews L, Viteri G, Gong C, Lorente P, Fabregat A, et al. The reactome pathway knowledgebase. Nucleic Acids Res. 2019. https://doi. org/10.1093/nar/gkz1031.

16. Sesarini CV, Costa L, Grañana N, Coto MG, Pallia RC, Argibay PF. Association between $\mathrm{GABA}(\mathrm{A})$ receptor subunit polymorphisms and autism spectrum disorder (ASD). Psychiatry Res. 2015;229(1-2):580-2.

17. Collins AL, Ma D, Whitehead PL, Martin ER, Wright HH, Abramson RK, et al. Investigation of autism and GABA receptor subunit genes in multiple ethnic groups. Neurogenetics. 2006;7(3):167-74.

18. Ma DQ, Whitehead PL, Menold MM, Martin ER, Ashley-Koch AE, Mei H, et al. Identification of significant association and gene-gene interaction of GABA receptor subunit genes in autism. Am J Hum Genet. 2005;77(3):377-88.

19. Buxbaum JD, Silverman JM, Smith CJ, Greenberg DA, Kilifarski M, Reichert J, et al. Association between a GABRB3 polymorphism and autism. Mol Psychiatry. 2002;7(3):311-6.

20. Delahanty RJ, Kang JQ, Brune CW, Kistner EO, Courchesne E, Cox NJ, et al. Maternal transmission of a rare GABRB3 signal peptide variant is associated with autism. Mol Psychiatry. 2011;16(1):86-96.

21. Kim SA, Kim JH, Park M, Cho IH, Yoo HJ. Association of GABRB3 polymorphisms with autism spectrum disorders in Korean trios. Neuropsychobiology. 2006;54(3):160-5.

22. Napoli E, Russo S, Casula L, Alesi V, Amendola FA, Angioni A, et al. ArrayCGH analysis in a cohort of phenotypically well-characterized individuals with "essential" autism spectrum disorders. J Autism Dev Disord. 2018:48(2):442-9.

23. Coghlan S, Horder J, Inkster B, Mendez MA, Murphy DG, Nutt DJ. GABA system dysfunction in autism and related disorders: from synapse to symptoms. Neurosci Biobehav Rev. 2012;36(9):2044-55.

24. Holt R, Barnby G, Maestrini E, Bacchelli E, Brocklebank D, Sousa I, et al. Linkage and candidate gene studies of autism spectrum disorders in European populations. Eur J Hum Genet EJHG. 2010;18(9):1013-9.

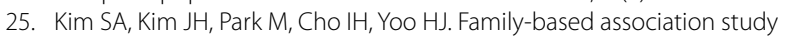
between GRIK2 polymorphisms and autism spectrum disorders in the Korean trios. Neurosci Res. 2007;58(3):332-5.

26. Pan Y, Chen J, Guo H, Ou J, Peng Y, Liu Q, et al. Association of genetic variants of GRIN2B with autism. Sci Rep. 2015;5(1):8296.

27. Barnby G, Abbott A, Sykes N, Morris A, Weeks DE, Mott R, et al. Candidategene screening and association analysis at the autism-susceptibility locus on chromosome 16p: evidence of association at GRIN2A and ABAT. Am J Hum Genet. 2005;76(6):950-66. 
28. Yuan H, Low C-M, Moody OA, Jenkins A, Traynelis SF. Ionotropic GABA and glutamate receptor mutations and human neurologic diseases. Mol Pharmacol. 2015;88(1):203-17.

29. Noroozi R, Taheri M, Movafagh A, Mirfakhraie R, Solgi G, Sayad A, et al. Glutamate receptor, metabotropic 7 ( GRM7) gene variations and susceptibility to autism: a case-control study: autism spectrum disorder and GRM7. Autism Res. 2016;9(11):1161-8.

30. Anderson BM, Schnetz-Boutaud NC, Bartlett J, Wotawa AM, Wright HH, Abramson RK, et al. Examination of association of genes in the serotonin system to autism. Neurogenetics. 2009;10(3):209-16.

31. Cho IH, Yoo HJ, Park M, Lee YS, Kim SA. Family-based association study of 5-HTTLPR and the 5-HT2A receptor gene polymorphisms with autism spectrum disorder in Korean trios. Brain Res. 2007;1139:34-41.

32. Hranilovic D, Blazevic S, Babic M, Smurinic M, Bujas-Petkovic Z, Jernej B. 5-HT2A receptor gene polymorphisms in Croatian subjects with autistic disorder. Psychiatry Res. 2010;178(3):556-8.

33. Banlaki Z, Elek Z, Nanasi T, Szekely A, Nemoda Z, Sasvari-Szekely M, et al. Polymorphism in the serotonin receptor 2a (HTR2A) Gene as possible predisposal factor for aggressive traits. Siegel A, editor. PLOS ONE. 2015:10(2):e0117792.

34. Sun L, Xu P, Zhou Y-G, Zuo S-R, Liu Y-P. Meta-analysis of polymorphism rs6311 and rs6313 in the 5-HT2AR gene and schizophrenia. Nord J Psychiatry. 2017;71(1):1-11.

35. Zhang G, Stackman RW. The role of serotonin 5-HT2A receptors in memory and cognition. Front Pharmacol. 2015;6:225.

36. Arieff Z, Kaur M, Gameeldien H, van der Merwe L, Bajic VB. 5-HTTLPR polymorphism: analysis in South African autistic individuals. Hum Biol. 2010;82(3):291-300.

37. Heils A, Teufel A, Petri S, Stöber G, Riederer P, Bengel D, et al. Allelic variation of human serotonin transporter gene expression. J Neurochem. 2002;66(6):2621-4.

38. McCauley JL, Olson LM, Dowd M, Amin T, Steele A, Blakely RD, et al. Linkage and association analysis at the serotonin transporter (SLC6A4) locus in a rigid-compulsive subset of autism. Am J Med Genet. 2004;127B(1):104-12.

39. Yirmiya N, Pilowsky T, Nemanov L, Arbelle S, Feinsilver T, Fried I, et al. Evidence for an association with the serotonin transporter promoter region polymorphism and autism. Am J Med Genet. 2001;105(4):381-6.

40. Conroy J, Meally E, Kearney G, Fitzgerald M, Gill M, Gallagher L. Serotonin transporter gene and autism: a haplotype analysis in an Irish autistic population. Mol Psychiatry. 2004;9(6):587-93.

41. Jaiswal P, Guhathakurta S, Singh AS, Verma D, Pandey M, Varghese $M$, et al. SLC6A4 markers modulate platelet 5-HT level and specific behaviors of autism: a study from an Indian population. Prog Neuropsychopharmacol Biol Psychiatry. 2015;56:196-206.

42. Sutcliffe JS, Delahanty RJ, Prasad HC, McCauley JL, Han Q, Jiang L, et al. Allelic heterogeneity at the serotonin transporter locus (SLC6A4) confers susceptibility to autism and rigid-compulsive behaviors. Am J Hum Genet. 2005;77(2):265-79.

43. Guhathakurta S, Sinha S, Ghosh S, Chatterjee A, Ahmed S, Gangopadhyay PK, et al. Population-based association study and contrasting linkage disequilibrium pattern reveal genetic association of SLC6A4 with autism in the Indian population from West Bengal. Brain Res. 2008;1240:12-21.

44. de Krom M, Staal WG, Ophoff RA, Hendriks J, Buitelaar J, Franke B, et al. A common variant in DRD3 receptor is associated with autism spectrum disorder. Biol Psychiatry. 2009;65(7):625-30.

45. Hettinger JA, Liu X, Schwartz CE, Michaelis RC, Holden JJA. A DRD1 haplotype is associated with risk for autism spectrum disorders in maleonly affected sib-pair families. Am J Med Genet B Neuropsychiatr Genet 2008;147B(5):628-36.

46. Li J, Zhao L, You Y, Lu T, Jia M, Yu H, et al. Schizophrenia related variants in CACNA1C also confer risk of autism. Zheng D, editor. PLOS ONE. 2015;10(7):e0133247.

47. Strom SP, Stone JL, ten Bosch JR, Merriman B, Cantor RM, Geschwind DH, et al. High-density SNP association study of the 17q21 chromosomal region linked to autism identifies CACNA1G as a novel candidate gene. Mol Psychiatry. 2010;15(10):996-1005.

48. Hernandez LM, Krasileva K, Green SA, Sherman LE, Ponting C, McCarron $\mathrm{R}$, et al. Additive effects of oxytocin receptor gene polymorphisms on reward circuitry in youth with autism. Mol Psychiatry. 2017;22(8):1134-9.
49. Wu S, Jia M, Ruan Y, Liu J, Guo Y, Shuang M, et al. Positive association of the oxytocin receptor gene (OXTR) with autism in the Chinese Han population. Biol Psychiatry. 2005;58(1):74-7.

50. Lerer E, Levi S, Salomon S, Darvasi A, Yirmiya N, Ebstein RP. Association between the oxytocin receptor (OXTR) gene and autism: relationship to Vineland Adaptive Behavior Scales and cognition. Mol Psychiatry. 2008:13(10):980-8.

51. Liu X, Solehdin F, Cohen IL, Gonzalez MG, Jenkins EC, Lewis MES, et al. Population- and family-based studies associate the MTHFR gene with idiopathic autism in simplex families. J Autism Dev Disord. 2011;41(7):938-44.

52. Toma C, Hervás A, Balmaña N, Salgado M, Maristany M, Vilella E, et al. Neurotransmitter systems and neurotrophic factors in autism: association study of 37 genes suggests involvement of DDC. World J Biol Psychiatry. 2013;14(7):516-27.

53. Chakraborti B, Verma D, Karmakar A, Jaiswal P, Sanyal A, Paul D, et al. Genetic variants of $M A O B$ affect serotonin level and specific behavioral attributes to increase autism spectrum disorder (ASD) susceptibility in males. Prog Neuropsychopharmacol Biol Psychiatry. 2016;03(71):123-36.

54. Yoo HJ, Lee SK, Park M, Cho IH, Hyun SH, Lee JC, et al. Family- and population-based association studies of monoamine oxidase $A$ and autism spectrum disorders in Korean. Neurosci Res. 2009;63(3):172-6.

55. Børglum AD, Bruun TG, Kjeldsen TE, Ewald H, Mors O, Kirov G, et al. Two novel variants in the DOPA decarboxylase gene: association with bipolar affective disorder. Mol Psychiatry. 1999;4(6):545-51.

56. Domschke K, Sheehan K, Lowe N, Kirley A, Mullins C, O'sullivan R, et al. Association analysis of the monoamine oxidase $A$ and $B$ genes with attention deficit hyperactivity disorder (ADHD) in an Irish sample: preferential transmission of the MAO-A 941G allele to affected children. Am J Med Genet Part B Neuropsychiatr Genet Off Publ Int Soc Psychiatr Genet. 2005:134B(1):110-4.

57. Meyer JH, Ginovart N, Boovariwala A, Sagrati S, Hussey D, Garcia A, et al. Elevated monoamine oxidase a levels in the brain: an explanation for the monoamine imbalance of major depression. Arch Gen Psychiatry. 2006;63(11):1209-16.

58. Guo T, Chen H, Liu B, Ji W, Yang C. Methylenetetrahydrofolate reductase polymorphisms C677T and risk of autism in the Chinese Han population. Genet Test Mol Biomark. 2012;16(8):968-73.

59. Mohammad NS, Jain JMN, Chintakindi KP, Singh RP, Naik U, Akella RRD Aberrations in folate metabolic pathway and altered susceptibility to autism. Psychiatr Genet. 2009;19(4):171-6.

60. Moll S, Varga EA. Homocysteine and MTHFR mutations. Circulation. 2015. https://doi.org/10.1161/CIRCULATIONAHA.114.013311.

61. Husemoen LLN, Skaaby T, Jørgensen T, Thuesen BH, Fenger M, Grarup $\mathrm{N}$, et al. MTHFR C677T genotype and cardiovascular risk in a general population without mandatory folic acid fortification. Eur J Nutr. 2014:53(7):1549-59.

62. Markan S, Sachdeva M, Sehrawat BS, Kumari S, Jain S, Khullar M. MTHFR 677 CT/MTHFR 1298 CC genotypes are associated with increased risk of hypertension in Indians. Mol Cell Biochem. 2007;302(1-2):125-31.

63. Rajagopalan P, Jahanshad N, Stein JL, Hua X, Madsen SK, Kohannim O, et al. Common folate gene variant, MTHFR C677T, is associated with brain structure in two independent cohorts of people with mild cognitive impairment. Neurolmage Clin. 2012;1(1):179-87.

64. Nabi R, Serajee FJ, Chugani DC, Zhong H, Huq AHMM. Association of tryptophan 2,3 dioxygenase gene polymorphism with autism. Am J Med Genet. 2004;125B(1):63-8.

65. Coon H, Dunn D, Lainhart J, Miller J, Hamil C, Battaglia A, et al. Possible association between autism and variants in the brain-expressed tryptophan hydroxylase gene ( TPH2). Am J Med Genet B Neuropsychiatr Genet 2005;135B(1):42-6.

66. Jonsson L, Anckarsäter $H$, Zettergren $A$, Westberg L, Walum $H$, Lundström $\mathrm{S}$, et al. Association between ASMT and autistic-like traits in children from a Swedish nationwide cohort. Psychiatr Genet. 2014;24(1):21-7.

67. Melke J, Goubran Botros H, Chaste P, Betancur C, Nygren G, Anckarsäter $\mathrm{H}$, et al. Abnormal melatonin synthesis in autism spectrum disorders. Mol Psychiatry. 2008;13(1):90-8.

68. Ramoz N, Cai G, Reichert JG, Corwin TE, Kryzak LA, Smith CJ, et al. Familybased association study of TPH1 and TPH2 polymorphisms in autism. Am J Med Genet B Neuropsychiatr Genet. 2006;141B(8):861-7. 
69. Südhof TC. Neuroligins and neurexins link synaptic function to cognitive disease. Nature. 2008:455(7215):903-11.

70. Nascimento PP, Bossolani-Martins AL, Rosan DBA, Mattos LC, BrandãoMattos C, Fett-Conte AC. Single nucleotide polymorphisms in the CNTNAP2 gene in Brazilian patients with autistic spectrum disorder. Genet Mol Res. 2016 [cited 2020 Oct 13];15(1). http://www.funpecrp.com.br/ gmr/year2016/vol15-1/pdf/gmr7422.pdf

71. Zare S, Mashayekhi F, Bidabadi E. The association of CNTNAP2 rs 7794745 gene polymorphism and autism in Iranian population. J Clin Neurosci. 2017;39:189-92

72. Li X, Hu Z, He Y, Xiong Z, Long Z, Peng Y, et al. Association analysis of CNTNAP2 polymorphisms with autism in the Chinese Han population. Psychiatr Genet. 2010;20(3):113-7.

73. Liu Y, Hu Z, Xun G, Peng Y, Lu L, Xu X, et al. Mutation analysis of the NRXN1 gene in a Chinese autism cohort. J Psychiatr Res. 2012;46(5):630-4.

74. Wang J, Gong J, Li L, Chen Y, Liu L, Gu H, et al. Neurexin gene family variants as risk factors for autism spectrum disorder. Autism Res Off J Int Soc Autism Res. 2018:11(1):37-43.

75. Landini M, Merelli I, Raggi M, Galluccio N, Ciceri F, Bonfanti A, et al. Association analysis of noncoding variants in neuroligins 3 and $4 X$ genes with autism spectrum disorder in an Italian cohort. Int J Mol Sci. 2016;17(10):1765.

76. Feng J, Schroer R, Yan J, Song W, Yang C, Bockholt A, et al. High frequency of neurexin 1 beta signal peptide structural variants in patients with autism. Neurosci Lett. 2006;409(1):10-3.

77. Xu X, Xiong Z, Zhang L, Liu Y, Lu L, Peng Y, et al. Variations analysis of NLGN3 and NLGN4X gene in Chinese autism patients. Mol Biol Rep. 2014;41(6):4133-40

78. Berkel S, Marshall CR, Weiss B, Howe J, Roeth R, Moog U, et al. Mutations in the SHANK2 synaptic scaffolding gene in autism spectrum disorder and mental retardation. Nat Genet. 2010:42(6):489-91.

79. Durand CM, Betancur C, Boeckers TM, Bockmann J, Chaste P, Fauchereau $F$, et al. Mutations in the gene encoding the synaptic scaffolding protein SHANK3 are associated with autism spectrum disorders. Nat Genet. 2007:39(1):25-7.

80. Leblond CS, Nava C, Polge A, Gauthier J, Huguet G, Lumbroso S, et al. Meta-analysis of SHANK mutations in autism spectrum disorders: A gradient of severity in cognitive impairments. Barsh GS, editor. PLoS Genet. 2014; 10(9):e1004580

81. Kelleher III RJ, Geigenmüller U, Hovhannisyan H, Trautman E, Pinard R, Rathmell $B$, et al. High-throughput sequencing of mGluR signaling pathway genes reveals enrichment of rare variants in autism. Esteban FJ, editor. PLOS ONE. 2012;7(4):e35003.

82. Chen C-H, Chen H-I, Liao H-M, Chen Y-J, Fang J-S, Lee K-F, et al. Clinical and molecular characterization of three genomic rearrangements at chromosome 22q13.3 associated with autism spectrum disorder. Psychiatr Genet. 2017;27(1):23-33.

83. Boccuto L, Lauri M, Sarasua SM, Skinner CD, Buccella D, Dwivedi A, et al. Prevalence of SHANK3 variants in patients with different subtypes of autism spectrum disorders. Eur J Hum Genet. 2013;21(3):310-6.

84. Bai Y, Qiu S, Li Y, Li Y, Zhong W, Shi M, et al. Genetic association between SHANK2 polymorphisms and susceptibility to autism spectrum disorder: SHANK2 POLYMORPHISMS IN ASD. IUBMB Life. 2018;70(8):763-76.
85. Lammert DB, Howell BW. RELN mutations in autism spectrum disorder. Front Cell Neurosci. 2016. https://doi.org/10.3389/fncel.2016.00084/abstr act.

86. Tian P. RELN gene polymorphisms and susceptibility to autism in Chinese Han population. Neurol India. 2012;60(6):581.

87. Ashley-Koch AE, Jaworski J, Ma DQ, Mei H, Ritchie MD, Skaar DA, et al. Investigation of potential gene-gene interactions between apoe and reln contributing to autism risk. Psychiatr Genet. 2007;17(4):221-6.

88. Sharma JR, Arieff Z, Gameeldien H, Davids M, Kaur M, van der Merwe L. Association analysis of two single-nucleotide polymorphisms of the RELN Gene with autism in the South African population. Genet Test Mol Biomark. 2013;17(2):93-8.

89. Wang G, Ye S, Gao L, Han Y, Guo X, Dong X, et al. Two single-nucleotide polymorphisms of the RELN gene and symptom-based and developmental deficits among children and adolescents with autistic spectrum disorders in the Tianjin. China Behav Brain Res. 2018;350:1-5.

90. Persico AM, D'Agruma L, Maiorano N, Totaro A, Militerni R, Bravaccio $C$, et al. Reelin gene alleles and haplotypes as a factor predisposing to autistic disorder. Mol Psychiatry. 2001;6(2):150-9.

91. Skaar DA, Shao Y, Haines JL, Stenger JE, Jaworski J, Martin ER, et al. Analysis of the RELN gene as a genetic risk factor for autism. Mol Psychiatry. 2005;10(6):563-71.

92. Essa MM, Braidy N, Vijayan KR, Subash S, Guillemin GJ. Excitotoxicity in the pathogenesis of autism. Neurotox Res. 2013;23(4):393-400.

93. Yenkoyan K, Grigoryan A, Fereshetyan K, Yepremyan D. Advances in understanding the pathophysiology of autism spectrum disorders. Behav Brain Res. 2017;331:92-101.

94. Craig AM, Kang Y. Neurexin-neuroligin signaling in synapse development. Curr Opin Neurobiol. 2007;17(1):43-52.

95. Dachtler J, Glasper J, Cohen RN, Ivorra JL, Swiffen DJ, Jackson AJ, et al. Deletion of a-neurexin II results in autism-related behaviors in mice. Transl Psychiatry. 2014;4:e484.

96. Etherton MR, Blaiss CA, Powell CM, Südhof TC. Mouse neurexin-1alpha deletion causes correlated electrophysiological and behavioral changes consistent with cognitive impairments. Proc Natl Acad Sci U S A. 2009;106(42):17998-8003.

97. Tetreault NA, Hakeem AY, Jiang S, Williams BA, Allman E, Wold BJ, et al. Microglia in the cerebral cortex in autism. J Autism Dev Disord. 2012;42(12):2569-84.

98. Araque A, Carmignoto G, Haydon PG, Oliet SHR, Robitaille R, Volterra A. Gliotransmitters travel in time and space. Neuron. 2014;81(4):728-39.

99. de Oliveira Pereira Ribeiro L, Vargas-Pinilla P, Kappel DB, Longo D, Ranzan J, Becker MM, et al. Evidence for association between OXTR gene and ASD clinical phenotypes. J Mol Neurosci MN. 2018;65(2):213-21.

\section{Publisher's Note}

Springer Nature remains neutral with regard to jurisdictional claims in published maps and institutional affiliations.

Ready to submit your research? Choose BMC and benefit from

- fast, convenient online submission

- thorough peer review by experienced researchers in your field

- rapid publication on acceptance

- support for research data, including large and complex data types

- gold Open Access which fosters wider collaboration and increased citations

- maximum visibility for your research: over 100M website views per year

At BMC, research is always in progress.

Learn more biomedcentral.com/submissions 